University of Nebraska - Lincoln

DigitalCommons@University of Nebraska - Lincoln

Faculty Papers and Publications in Animal

Science

Animal Science Department

May 1976

\title{
POSTWEANING PERFORMANCE AND CARCASS MERIT OF PUREBRED AND TWO-BREED CROSS PIGS
}

\author{
L. D. Young \\ Oklahoma Agricultural Experiment Station, Stillwater \\ R. K. Johnson \\ University of Nebraska-Lincoln, rjohnson5@unl.edu \\ I. T. Omtvedt \\ U.S. Department of Agriculture, El Reno, iomtvedt1@unl.edu \\ L. E. Walters \\ Oklahoma Agricultural Experiment Station, Stillwater
}

Follow this and additional works at: https://digitalcommons.unl.edu/animalscifacpub

Part of the Animal Sciences Commons

Young, L. D.; Johnson, R. K.; Omtvedt, I. T.; and Walters, L. E., "POSTWEANING PERFORMANCE AND CARCASS MERIT OF PUREBRED AND TWO-BREED CROSS PIGS" (1976). Faculty Papers and Publications in Animal Science. 77.

https://digitalcommons.unl.edu/animalscifacpub/77

This Article is brought to you for free and open access by the Animal Science Department at DigitalCommons@University of Nebraska - Lincoln. It has been accepted for inclusion in Faculty Papers and Publications in Animal Science by an authorized administrator of DigitalCommons@University of Nebraska - Lincoln. 


\title{
POSTWEANING PERFORMANCE AND CARCASS MERIT OF PUREBRED AND TWO-BREED CROSS PIGS ${ }^{1}$
}

\author{
L. D. Young ${ }^{2}$, R. K. Johnson ${ }^{2}$, I. T. Omtvedt ${ }^{3}$ and L. E. Walters ${ }^{2}$ \\ Oklaboma Agricultural Experiment Station, Stillwater 74074 and \\ U.S. Department of Agriculture, El Reno 73036
}

\section{SUMMARY}

The feedlot records of 2,111 purebred and crossbred pigs representing all purebred and all possible two-way crosses of Duroc, Hampshire and Yorkshire were analyzed to evaluate average daily gain on test, age at $100 \mathrm{~kg}$, average backfat probe of gilts, average daily feed consumption and feed conversion. A random sample of 392 barrows was used to evaluate carcass traits. The data were analyzed to determine breed of sire and breed of dam effects, to evaluate differences between reciprocal crosses and to estimate heterosis.

Breed of sire and breed of dam effects were significant for many of the traits evaluated. Straightbred Durocs had a higher average daily gain, were fatter and produced carcasses that were firmer and had more marbling than straightbred Hampshires or Yorkshires $(\mathbf{P}<.05)$. Yorkshires were the most efficient straightbred while Hampshires had the largest longissimus muscle areas and leanest carcasses of the straightbreds.

Significant differences were noted between reciprocal crosses. When Yorkshires were involved in the cross, the pigs were more efficient, consumed less feed per day and produced carcasses that were leaner and had larger longissimus muscle areas when the Yorkshire was used as the dam rather than as the sire $(P<.05)$.

Significant and favorable heterosis was found for average daily gain, age at $100 \mathrm{~kg}$, feed efficiency, feed consumption and carcass length

\footnotetext{
'Journal Article 3000 of the Agricultural Experiment Station, Oklahoma State University, Stillwater. Research conducted by the Department of Animal Science and Industry (Project 1444) in cooperation with the U.S.D.A., Agricultural Research Service, Southern Region.

${ }^{2}$ Department of Animal Science and Industry, Oklahoma State University Stillwater $\mathbf{7 4 0 7 4 .}$

${ }^{3}$ Department of Animal Science, University of Nebraska, Lincoln, 68503.
}

when averaged over all crosses. The general lack of heterosis for carcass traits indicates that the carcass merit of crossbred pigs can be approximated by the average of the purebreds involved in the cross.

(Key Words: Swine Crossbreeding, Feedlot, Carcass Traits.)

\section{INTRODUCTION}

There are very few crossbreeding studies involving "modern" swine breeds that evaluate postweaning performance or carcass merit of pigs raised under confinement conditions. Those that have been conducted, were primarily interested in estimating heterosis. Consequently, there is little information on specific crossing sequences or how to combine breeds to produce an overall superior market pig.

Johnson et al. (1973) reported the results of two replications of an experiment designed to evaluate postweaning performance and carcass merit of pigs produced by making all possible purebred and two-way cross matings of Duroc, Hampshire and Yorkshire. Since then, two additional replications were completed in this project to yield data from a total of four replications for this study. The addition of two seasons of data more than doubled the number of observations and thus greatly increased the precision of the estimates.

\section{MATERIALS AND METHODS}

The data for this paper came from four replications of Phase I of the Oklahoma swine crossbreeding project conducted at the Fort Reno Experiment Station. Distribution of pigs, litters and pens used in the analyses of the various traits are given by breed group in table 1. A total of 2,111 records of pigs from 362 litters with 70 different sires were used to evaluate average daily gain on test and age at 100 kilograms. Backfat probe was evaluated on 
TABLE 1. DISTRIBUTION OF PIGS BY BREED GROUP FOR TRAITS MEASURED

\begin{tabular}{|c|c|c|c|c|}
\hline $\begin{array}{l}\text { Breed } \\
\text { group }\end{array}$ & $\begin{array}{l}\text { No. of pigs for } \\
\text { avg daily gain } \\
\text { and age at } 100 \mathrm{~kg}^{\mathrm{a}}\end{array}$ & $\begin{array}{l}\text { No. of giits } \\
\text { used for } \\
\text { backfat probe }\end{array}$ & $\begin{array}{l}\text { No. of pens } \\
\text { used for feed } \\
\text { efficiency and } \\
\text { consumption }\end{array}$ & $\begin{array}{l}\text { No. of } \\
\text { barrows for } \\
\text { carcass data }\end{array}$ \\
\hline Total & $2111(362)$ & $1054(337)$ & 142 & 392 \\
\hline$D \times D$ & $183(41)$ & $93(35)$ & 17 & 43 \\
\hline $\mathrm{H} \times \mathrm{H}$ & $172(42)$ & $87(39)$ & 16 & 46 \\
\hline$Y \times Y$ & $240(42)$ & $126(40)$ & 23 & 44 \\
\hline $\mathrm{D} \times \mathrm{H}$ & $260(44)$ & $136(42)$ & 17 & 45 \\
\hline $\mathrm{D} \times \mathrm{Y}$ & $277(37)$ & $147(35)$ & 15 & 41 \\
\hline$H \times D$ & $211(34)$ & $102(30)$ & 11 & 42 \\
\hline$H \times Y$ & $198(34)$ & $94(32)$ & 12 & 41 \\
\hline$Y \times D$ & $290(43)$ & $136(42)$ & 17 & 44 \\
\hline $\mathrm{Y} \times \mathrm{H}$ & $280(45)$ & $133(42)$ & 14 & 46 \\
\hline
\end{tabular}

${ }^{\mathbf{a}}$ Numbers in parentheses indicate number of litters.

gilts only and 1,054 records of backfat probe on gilts from 337 litters were included in the analysis. Feed efficiency (kg gain $/ \mathrm{kg}$ feed) and average daily feed consumption per pig were evaluated on 142 pens. A random sample of 392 barrows was used to evaluate carcass traits.

The formation and maintenance of the seedstock herds at the Stillwater Experimental Swine Farm which provided the purebred males and females for this project have previously been described by Johnson et al. (1973). Methods of herd management and data collection have also been described in detail by the above authors.

Pigs were farrowed in the spring and fall of 1971 and 1973 at both the $\mathrm{Ft}$. Reno Station and the Stillwater Station. Because purebred litters contained fewer pigs at weaning, purebred pigs from Stillwater were transferred to $\mathrm{Ft}$. Reno at weaning and were allotted on test with Ft. Reno purebreds. Since all purebred boars and most purebred gilts used at Ft. Reno came from Stillwater, both sources of purebred pigs were of comparable breeding and the use of Stillwater pigs should not bias the purebredcrossbred comparison. Tests of significance indicated no significant difference in the performance of purebred pigs from the two stations. Purebred pigs from Stillwater were not used for average daily gain, age at $100 \mathrm{~kg}$ or backfat probe because sires were included in the model for anlayzing these traits. If Stillwater purebreds were in the analyses, the fact that boars that sired Stillwater pigs would be represented in only one breed group, would have resulted in an ill-conditioned matrix and difficult analyses. Stillwater purebreds were involved in the analyses of feed efficiency and average daily feed consumption because often a pen would contain purebreds from both stations and these traits were evaluated on a pen basis. Purebreds from Stillwater were also included in the analyses of carcass traits.

Litter means were used as the experimental unit in the analyses of average daily gain, age at $100 \mathrm{~kg}$ and backfat probe. Average daily gain and age at $100 \mathrm{~kg}$ were evaluated on a barrow basis and backfat probe was only on gilts. Gilt records were adjusted to a barrow equivalent based on the observed average difference between barrows and gilts. Gilt records were adjusted to a barrow equivalent by adding $.0566 \mathrm{~kg}$ to average daily gain and subtracting 7.70 days from age at 100 kilograms. It was considered necessary to include sire in the model as a random effect and available computer programs could not do this with full sib data, therefore unadjusted litter means were used as experimental units. The experimental units for feed efficiency and average daily feed consumption per pig were pen means. Pens were composed of various combinations of barrows and gilts and no adjustments were made for this type of variation.

Data were analyzed by the least squares procedures for disproportionate subclasses described by Harvey (1960) and supplemented by Harvey (1972). The model used to analyze average daily gain, age at $100 \mathrm{~kg}$ and backfat probe was: $Y_{i j k m}=\mu+B_{i}+s_{j(i)}+D_{k}+B D_{i k}+$ $e_{i j k m}$ where $Y_{i j k m}=$ observed value of the dependent variable for the $\mathrm{m}^{\text {th }}$ litter in $i j k^{\text {th }}$ 
subclass, $\mu=$ fitted mean, $B_{i}=$ effect of the $i^{\text {th }}$ sire breed, $s_{j(i)}=$ effect of the $j^{\text {th }}$ sire in the $i^{\text {th }}$ sire breed, $D_{k}=$ effect of the $k^{\text {th }}$ dam breed, $\mathrm{BD}_{\mathrm{ik}}=$ interaction of the $\mathrm{i}^{\text {th }}$ sire breed and the $\mathrm{k}^{\text {th }}$ dam breed and $\mathrm{e}_{\mathbf{i j k m}}=$ random element. All effects except $s_{j(i)}$ and $e_{i j k m}$ were considered fixed effects and $s_{j(i)}$ and $e_{i j k m}$ were considered random effects with zero mean and variances $\sigma_{\mathrm{s}}^{2}$ and $\sigma^{2}$, respectively. This model and linear contrasts among least squares means were fit within season and pooled over season giving equal weight to each season. The sire mean square was used for the error term for all comparisons except comparisons among breeds of dam and heterosis estimates. The error mean square was used as the error term for the latter two contrasts.

The model used to analyze feed efficiency, average daily feed consumption and carcass traits was: $Y_{i j k m}=\mu+R_{i}+B_{j}+D_{k}+R B_{i j}+$ $R D_{i k}+B D_{j k}+e_{i j k m}$ where $Y_{i j k m}=$ observed value of the dependent variable for the $\mathrm{m}^{\text {th }}$ pen or pig in the $i j k^{\text {th }}$ subclass, $\mu=$ fitted mean, $R_{i}$ $=$ effect of the $i^{\text {th }}$ season, $B_{j}=$ effect of $j^{\text {th }}$ sire breed, $D_{k}=$ effect of $k^{\text {th }}$ dam breed and $R_{i j}$, $R D_{i k}$ and $B D_{j k}=$ interaction effects and $e_{i j k m}$ $=$ random element. In the analysis of percent lean cuts of the carcass, live weight was added as a covariable. Linear contrasts among least squares means and their standard errors were calculated. Sires could not be included in the analyses of feed efficiency and average daily feed consumption since progeny from more than one sire were included in a pen mean. Sires were not included in the analyses of carcass traits since Stillwater purebreds were included in the slaughter sample and some boars were represented in only one breed group, thus creating a dependency structure in the data and making the analyses very difficult. The deletion of sires should have its largest effect on the more highly heritable carcass traits. However, Bereskin et al. (1971) found sires to be a significant source of variation only for longissimus muscle area and percent ham and loin. In their analyses, ignoring the effect of sires would have had little effect on significance levels.

Within each type of comparison, more comparisons are made than there are degrees of freedom. Contrasts were made to answer questions of interest without regard to the orthogonality or linear independence of the contrasts.

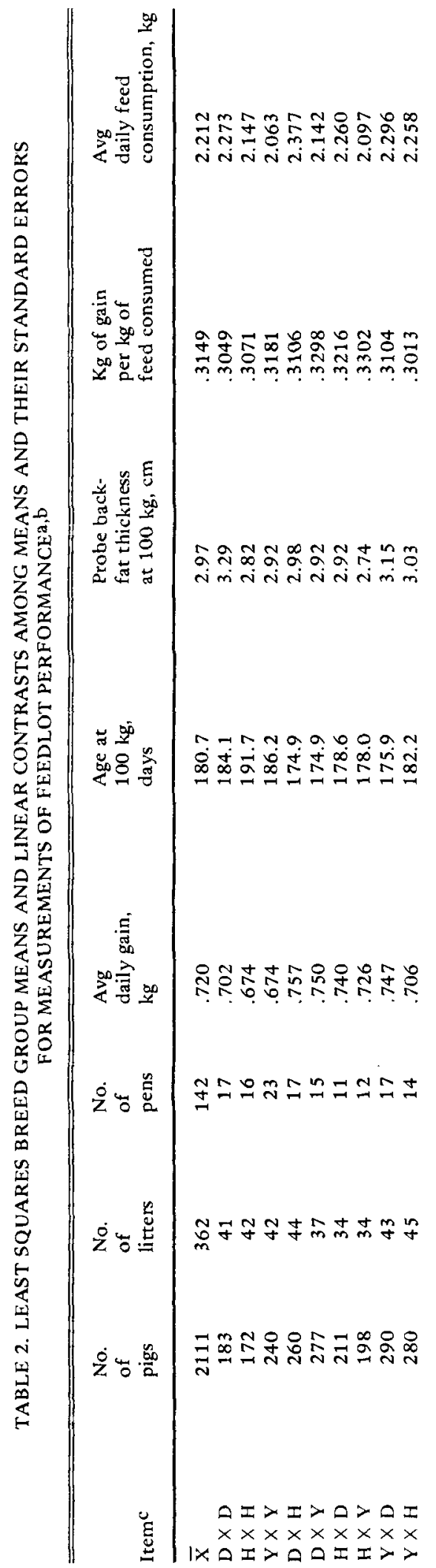




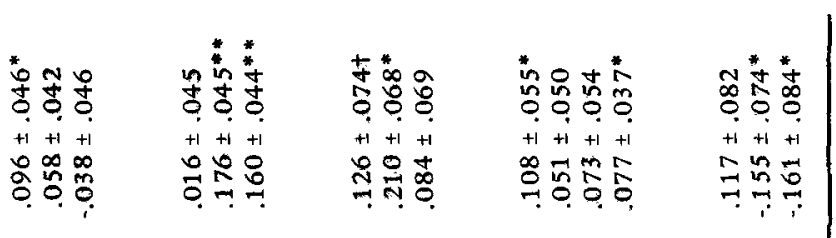

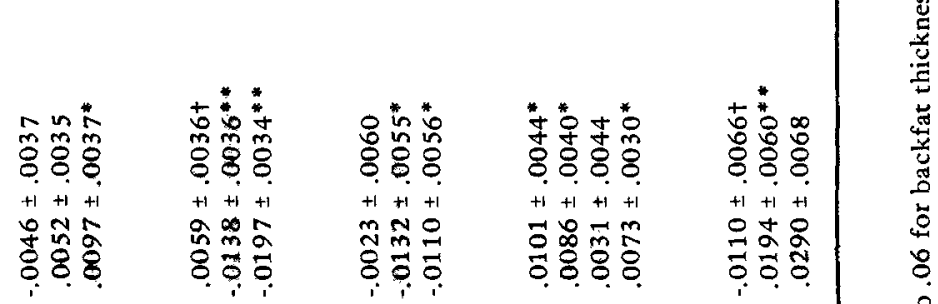

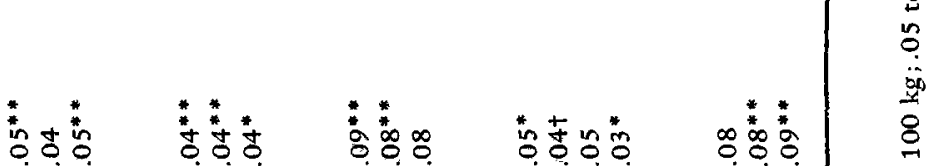

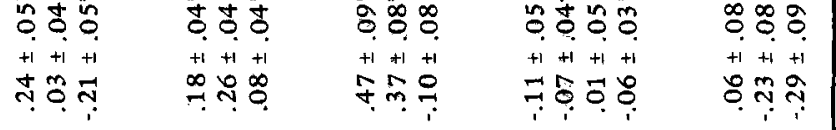

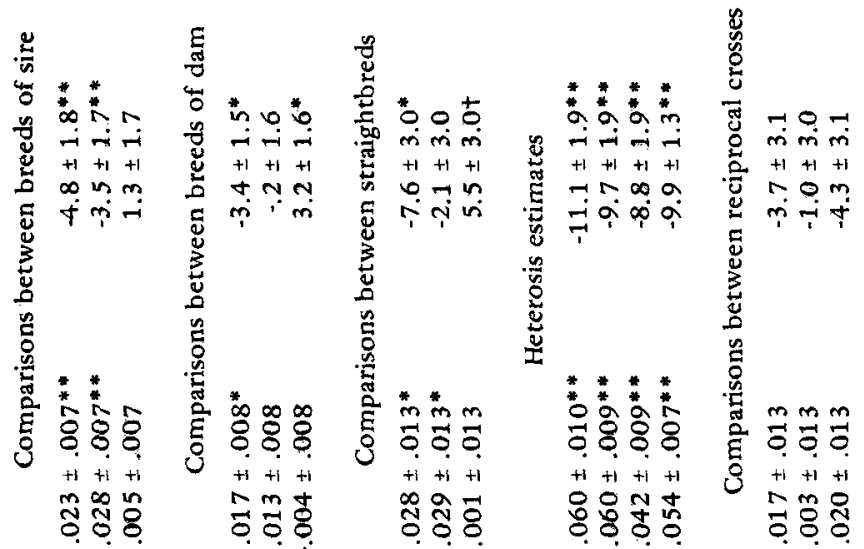

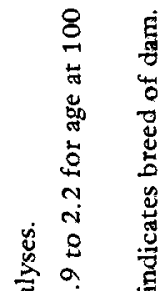

n $\infty$ in in 0 :

$\begin{array}{lll}+1+1+1 & \mathbb{2} & +1\end{array}$

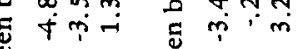

잉.

ํ. 0

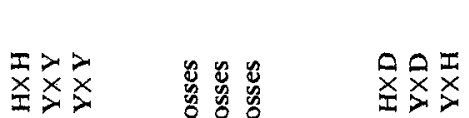

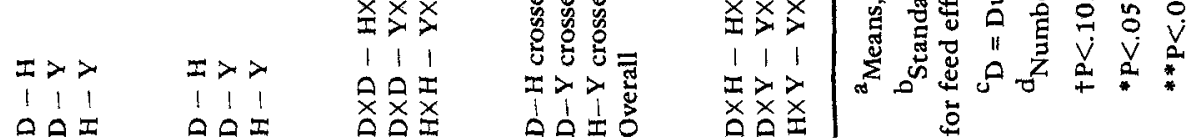




\section{RESULTS AND DISCUSSION}

\section{Feedlot Performance}

The least squares means and linear contrasts among least squares means for feedlot performance traits are presented in table 2 .

Comparisons between Breeds of Sire. Duroc sired pigs grew faster $(\mathrm{P}<01)$ and consequently were younger at $100 \mathrm{~kg}(\mathrm{P}<.05)$ than Hampshire or Yorkshire sired pigs with no significant difference between Hampshire and Yorkshire sired pigs for these two traits. Hampshire sired gilts had significantly less backfat than either Duroc or Yorkshire sired gilts while the difference in backfat thickness of gilts sired by the latter two breeds was neither large nor significant. Pigs sired by Hampshire boars consumed significantly less feed per day than pigs out of Duroc boars and were significantly more efficient than pigs sired by Yorkshire boars.

Comparisons between Breeds of Dam. Pigs out of Duroc dams had a higher average daily gain $(\mathrm{P}<.05)$ were younger $(\mathrm{P}<.05)$ and fatter at $100 \mathrm{~kg} \quad(\mathrm{P}<.01)$ and were more efficient $(\mathrm{P}<.01)$ than pigs out of Hampshire dams. Yorkshire females produced pigs that had less backfat, were more efficient and consumed less feed per day than pigs produced by Duroc or Hampshire females $(\mathrm{P}<.05$ to $\mathrm{P}<.01)$. Pigs out of Yorkshire dams were also younger at $100 \mathrm{~kg}$ $(\mathrm{P}<.05)$ than pigs out of Hampshire dams.

Comparisons between Straightbreds. The straightbred Durocs grew faster $(\mathbf{P}<.05)$ than straightbred Hampshires or Yorkshires while essentially no difference was observed between the latter two straightbred groups for average daily gain. Straightbred Hampshires were older at $100 \mathrm{~kg}$ than either straightbred Durocs $(\mathrm{P}<.05)$ or Yorkshires $(\mathrm{P}<.10)$. Very little difference was found between Hampshires and Yorkshires for average backfat thickness; however, both groups had less backfat than Durocs $(\mathrm{P}<.01)$. Yorkshires were the most efficient straightbred group $(\mathrm{P}<.05)$ while Durocs consumed more feed per day than Hampshires $(\mathrm{P}<.10)$ or Yorkshires $(\mathrm{P}<.05)$. The differences in growth rate of these three breeds in this study are in agreement with those found by Hale and Southwell, (1967) Bruner and Swiger (1968) and Quijandria et al. (1970). Hale and Southwell, (1967) found that Durocs were more efficient than Hampshires while Bruner and Swiger (1968) and Quijandria et al. (1970) found Durocs were more efficient than Hampshires or Yorkshires. The differences in age at
$100 \mathrm{~kg}$ found in this study are in agreement with those found by Quijandria et al. (1970).

Heterosis Estimates. Heterosis was estimated as the average performance of reciprocal crosses minus the average performance of the purebreds involved in the cross. All crosses exhibited heterosis $(\mathrm{P}<.01)$ for average daily gain and age at $100 \mathrm{~kg}$ and the amount of heterosis expressed was similar for each specific cross for both traits. Overall, crossbred pigs gained .05 \pm $.007 \mathrm{~kg}$ more per day and were $9.9 \pm 1.3$ days younger at $100 \mathrm{~kg}$ than purebreds. Crosses involving Durocs expressed favorable heterosis for backfat probe at $100 \mathrm{~kg}$ and feed efficiency. On an overall basis, crossbred pigs had $.06 \pm .03$ $\mathrm{cm}$ less backfat and gained .0073 $\pm .0300 \mathrm{~kg}$ more per kilogram of feed consumed than purebreds. Heterosis estimates for average daily feed consumption were consistent in sign; however, only the estimate for Duroc-Hampshire crosses was significant. Overall, crossbred pigs consumed more feed per day $(\mathbf{P}<.05)$ than purebreds.

In agreement with this study, several researchers have reported that crossbreds gained faster than purebreds (Carroll and Roberts, 1942; Gregory and Dickerson, 1952; England and Winters, 1953; Gaines and Hazel, 1957; Smith et al., 1960). The heterosis estimate of $.054 \mathrm{~kg}$ per day found in this study is on the upper end of the range of values found in the literature.

In this study, crossbreds gained more efficiently and consumed more feed per day than purebreds. Lush et al. (1939), Tucker et al. (1952), Whatley et al. (1960) and Kuhlers et al. (1972) also reported that crossbreds averaged less feed per kilogram of gain than straightbreds. Tucker et al. (1952) reported that crossbreds consumed more feed per day than purebreds while Kuhlers et al. (1972) reported little difference in average daily feed consumption between purebreds and crossbreds.

Comparisons among Reciprocal Crosses. No significant differences were found between reciprocal crosses for average daily gain or age at 100 kilograms. Hampshire-Duroc pigs produced by Duroc dams gained more efficiently than when produced by Hampshire dams $(\mathrm{P}<10)$. When Yorkshires were involved in the cross, the pigs had less backfat $(\mathrm{P}<.01)$, were more efficient $(\mathrm{P}<.01)$ and consumed less feed per day $(\mathrm{P}<.05)$ when the Yorkshire was used as the female. Since the genetic composition of reciprocally produced pigs is expected to be the 
same (assuming no cytoplasmic inheritance), any difference in the performance of these pigs is probably due to a maternal effect of the dam. Assuming that the sampling of the breeds were equal for sires and dams, these data indicate that in crossbred litter production Yorkshire females provide a maternal environment prior to weaning that causes their pigs to be leaner, more efficient and consume less feed per day than the same breed combination of pigs out of Duroc or Hampshire dams.

\section{Carcass Traits}

The least squares breed group means and linear contrasts among means for carcass traits are presented in table 3.

Comparisons between Breeds of Sire. A large number of differences were found between breeds of sire. Duroc sired pigs produced carcasses that were shorter than carcasses of pigs sired by Hampshires or Yorkshires $(\mathrm{P}<.01)$. Hampshire boars sired pigs with the least carcass backfat and largest longissimus muscle areas while Yorkshire boars sired pigs with the most carcass backfat and smallest longissimus muscle areas $(\mathrm{P}<05)$. Total lean cut yield as a percent of carcass weight ranked the three sire breeds from highest to lowest in the order; Hampshire, Duroc and Yorkshire, with all differences significant. Duroc boars sired pigs that produced longissimus muscles that were more marbled, firmer and less pale in color than carcasses produced by pigs sired by either Hampshire or Yorkshire boars $(\mathrm{P}<.01)$. The differences between the latter two sire breeds for these traits were essentially zero.

Comparisons between Breeds of Dam. The comparison of Duroc and Hampshire dams produced results similar to the comparison of Duroc and Hampshire sires. Comparisons involving Yorkshire dams produced results somewhat different than the same comparisons involving Yorkshire sires. The longest carcasses were from pigs produced by Yorkshire females followed by those produced by Hampshire females $(\mathbf{P}<.05)$. Duroc dams produced pigs whose carcasses had significantly more backfat, smaller longissimus muscle areas and a smaller percent lean of the carcass than pigs from Yorkshire or Hampshire dams. The difference between the latter two breeds for these traits was significant only for percent lean of the carcass. Duroc dams produced pigs that had longissimus muscles that were more marbled and firmer than those of pigs from dams of the other two breeds $(P<.01)$. Hampshire females produced pigs whose longissimus muscles were significantly lighter and softer than those of pigs from Duroc or Yorkshire females.

Comparisons between Straightbreds. Straightbred Hampshires produced carcasses that had less backfat, larger longissimus muscle areas and a higher percent lean of the carcass than carcasses from straightbred Durocs or Yorkshires $(\mathrm{P}<.01)$. Hampshire carcasses were longer than Duroc carcasses $(P<.01)$ but shorter than Yorkshire carcasses $(P<.10)$. Straightbred Duroc carcasses had a smaller percent lean of the carcass $(\mathrm{P}<.01)$ than straightbred Yorkshires. The differences found between the three pure breeds in this study agree with differences reported by Hale and Southwell (1967), Jensen et al. (1967), Bruner and Swiger (1968) and Quijandria et al. (1970).

Longissimus muscles from Duroc carcasses were firmer and had more marbling than those from either Hampshire or Yorkshire carcasses $(\mathrm{P}<.01)$. Hampshire longissimus muscles had a significantly lower color score than those from Durocs or Yorkshires and were significantly softer than those from Yorkshires. Jensen $e t$ al. (1967) also found that Duroc carcasses were firmer and had more marbling than Hampshire or Yorkshire carcasses with no difference between the latter two for these traits. In contrast, to this study, Jensen et al. found Yorkshires had the highest color score and Hampshires the lowest color score. Judge et al. (1959) and Otto (1962) also reported significant breed differences for meat color.

Heterosis Estimates. There were few significant heterosis estimates for carcass traits. The only overall heterosis estimate that was significant was for carcass length and it was the result of significant positive heterosis exhibited by crosses involving Duroc, the shortest straightbred. No significant heterosis was found for carcass backfat or longissimus muscle area. Duroc-Yorkshire crosses did exhibit positive heterosis for percent lean cuts of the carcass $(\mathrm{P}<10)$. Hetzer et al. (1951), Tucker et al. (1952), Whatley et al. (1960), Kuhlers et al. (1972) and Gregory and Dickerson (1952) also found little difference in the carcass traits of crossbreds and purebreds. However, in agreement with this study, the first three authors did indicate that crossbred carcasses were longer than purebred carcasses. Bereskin et al. (1971) reported that crossbreds averaged $.23 \mathrm{~cm}$ less 


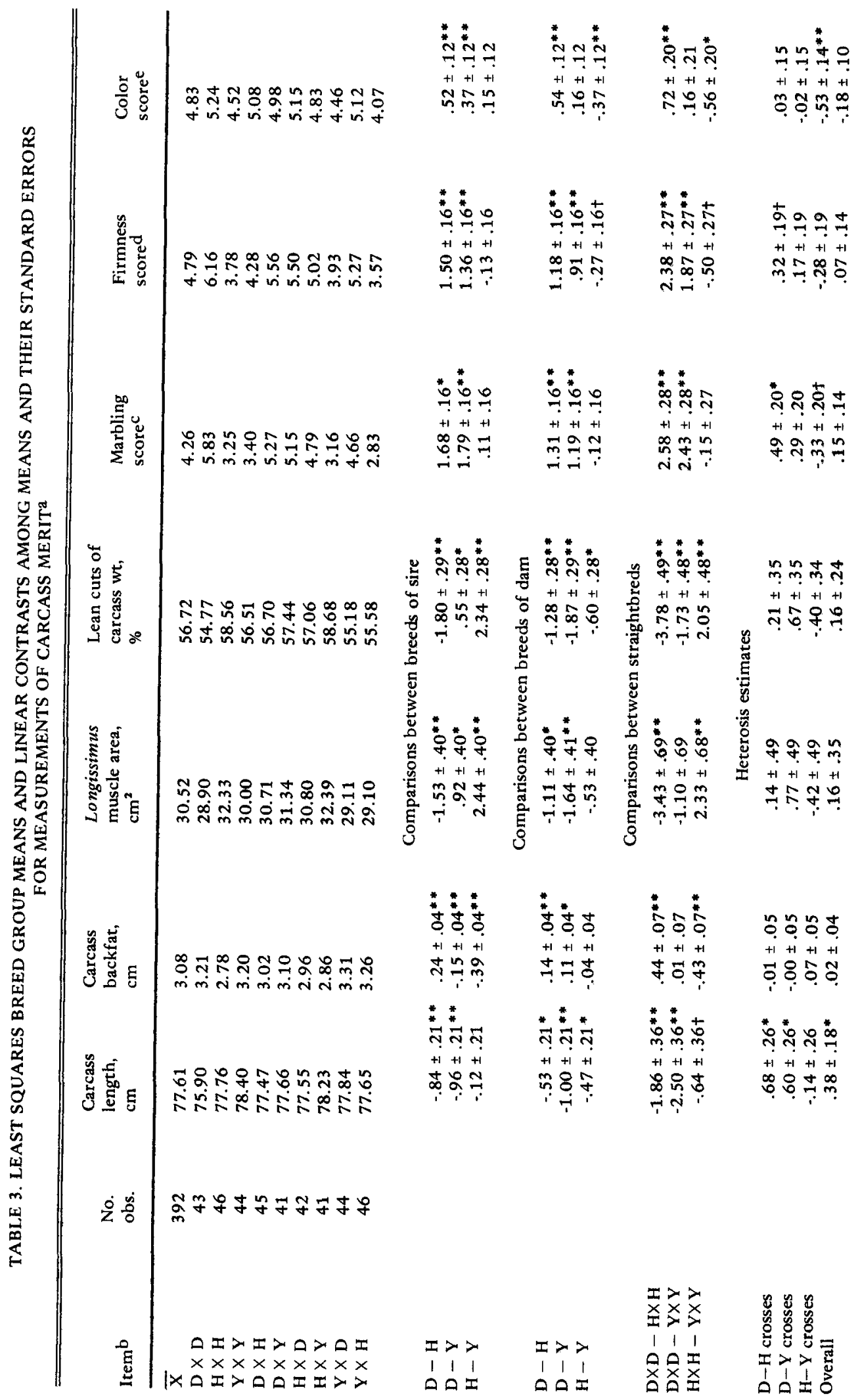




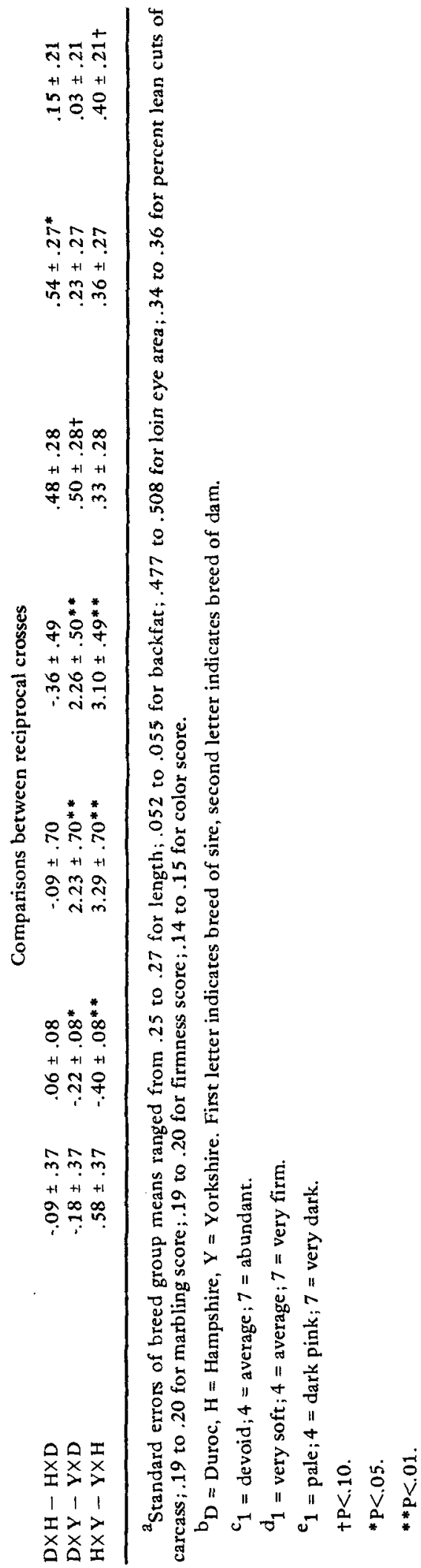

backfat, .4\% more ham and . $28 \%$ more ham and loin than the average of the parental purebred Durocs and Yorkshires.

Duroc-Hampshire crosses exhibited positive heterosis for marbling score $(P<.05)$ and firmness score $(\mathrm{P}<10)$. However, crosses among Hampshires and Yorkshires expressed negative heterosis for marbling score $(\mathrm{P}<.10)$ and color score $(\mathrm{P}<.01)$.

The lack of consistent and significant heterosis estimates for the carcass traits evaluated indicate that the carcass merit of crossbred pigs can be approximated by the average of the purebreds involved in the cross.

Comparisons among Reciprocal Crosses. Duroc-Hampshire crossbred pigs produced by Hampshire dams produced firmer longissimus muscles than the same breed combination out of Duroc dams $(\mathrm{P}<.05)$. When Yorkshires were used as the female, the pigs had less carcass backfat, larger longissimus muscle area and a higher percent of lean cuts in the carcass $(P<.05)$. As in the feedlot data, this indicates a difference in the maternal effects of the Yorkshire dams vs the Hampshire and Duroc dams. The Yorkshire female provides a maternal environment prior to weaning which causes her pigs to produce a leaner more heavily muscled carcass than the same breed combination out of Duroc or Hampshire dams. The differences between reciprocal crosses of Durocs and Yorkshires in this study are in agreement with those reported by Bereskin et al. (1971) and support their conclusion of the presence of a large maternal effect on carcass traits.

These data indicate that significant and favorable heterosis can be expected for average daily gain, age at $100 \mathrm{~kg}$, feed efficiency, average daily feed consumption and carcass length. Little heterosis is expected for other carcass traits.

The differences in reciprocal crosses indicate that if Yorkshires are to be involved in the cross, they should be used as the dam breed. Crosses involving the Yorkshire are more efficient in the feedlot and produce carcasses that are leaner and more heavily muscled when the Yorkshire is used as the dam rather than as the sire.

\section{LITERATURE CITED}

Bereskin, B., C. E. Shelby and L. N. Hazel. 1971. Carcass traits of purebred Durocs and Yorkshires and their crosses. J. Anim. Sci. 32:413. 
Bruner, W. H. and L. H. Swiger. 1968. Effects of sex, season and breed on live and carcass traits at the Ohio swine evaluation station. J. Anim. Sci. 27:383.

Carroll, W. E. and E. Roberts. 1942. Crossbreeding in swine: Does it offer an effective method for improvement of market hogs? Ill. Agr. Exp. Sta. Bull. 489.

England, D. C. and L. M. Winters. 1953. The effects of genetic diversity and performance of inbred lines per se on hybrid vigor in swine. J. Anim. Sci. $12: 836$.

Gaines, J. A. and L. N. Hazel, 1957. Differences in litter size and growth rate among purebred and crossbred swine. J. Anim. Sci. 16:1066. (Abstr.).

Gregory, K. E. and G. E. Dickerson. 1952. Influence of heterosis and plane of nutrition on rate and econumy of gains, digestion and carcass composition of pigs. Mo. Agr. Res. Bull. 493.

Hale, O. M. and B. L. Southwell. 1967. Differences of swine performance and carcass characteristics because of dietary protein level, sex and breed. J. Anim. Sci. 26:341.

Harvey, W. R. 1960. Least squares analysis of data with unequal subclass numbers. U.S.D.A. Pub. A.R.S. 20-8.

Harvey, W. R. 1972. General Outline of Computing Procedures for Six Types of Mixed Models. (Mimeo.)

Hetzer, H. O., O. G. Hankins and J. H. Zeller. 1951. Performance of crosses between six inbred lines of swine. U.S.D.A. Cir. No. 893.

Jensen, P., H. B. Craig and O. W. Robison. 1967. Phenotypic and genetic associations among carcass traits of swine. J. Anim. Sci. 26:1252.
Johnson, R. K., I. T. Omtvedt and L. E. Walters. 1973. Evaluation of purebreds and two-breed crosses in swine: Feedlot performance and carcass merit. J. Anim. Sci. 37:18.

Judge, M. D., V. R. Cahill, L. E. Kunkle and W. H. Bruner. 1959. Pork quality. I. Influences of some factors on pork muscle characteristics. J. Anim. Sci. 18:448.

Kuhlers, D. L., A. B. Chapman and N. L. First. 1972. Estimates of genotype environment interactions in production and carcass traits in swine. J. Anim. Sci. 35:1.

Lush, J. L., P. S. Shearer and C. C. Culbertson. 1939. Crossbreeding hogs for pork production. Iowa Agr. Exp. Sta. Bull. 380.

Otto, E. 1962. Determining color and muscle fiber diameter of meat and the effects of breed, sex, sire and dam on them. VIII. Int. Congs. Anim. Prod. III. 211. (Animal Breed. Abstr. 31:87.).

Quijandria, B., Jr., J. R. Woodard and $O$. W. Robison. 1970. Genetic and environmental effects on live and carcass traits at the North Carolina swine evaluation station. J. Anim. Sci. 31:652.

Smith, H. J., R. P. Moorman and J. B. McLaren. 1960. Performance of straightbred and crossbred swine. J. Anim. Sci. 19:1227 (Abstr.).

Tucker, H. F., G. E. Dickerson and J. F. Lasley. 1952. Crossbreeding effects on growth, digestion, feed utilization and carcass composition in swine under full and equalized feeding with and without antibiotic. J. Anim. Sci. 11:745. (Abstr.).

Whatley, J. A., Jr., S. P. Wilson and I. T. Omtvedt. 1960. Performance tests with purebred and crossbred pigs from two lines of breeding. Okla. Agr. Exp. Sta. Misc. Pub. 57:50. 